\title{
Article \\ Overlap Arrhythmia Syndromes Resulting from Multiple Genetic Variations Studied in Human Induced Pluripotent Stem Cell-Derived Cardiomyocytes
}

\author{
Jacqueline A. Treat ${ }^{1}$, Ryan Pfeiffer ${ }^{1}$, Hector Barajas-Martinez ${ }^{2}$, Robert J. Goodrow ${ }^{1}$, Corina Bot ${ }^{3}$, \\ Rodolfo J. Haedo ${ }^{3}$, Ronald Knox ${ }^{3}$ and Jonathan M. Cordeiro ${ }^{1, * \mathbb{D}}$ \\ 1 Department of Experimental Cardiology, Masonic Medical Research Institute, Utica, NY 13501, USA \\ incredimomj@hotmail.com (J.A.T.); pfeifferr@mmri.edu (R.P.); goodrowr@mmri.edu (R.J.G.) \\ 2 Department of Cardiovascular Research, Lankenau Institute for Medical Research, \\ Wynnewood, PA 19096, USA; barajasmartinezh@mlhs.org \\ 3 Nanion Technologies, 1 Naylon Ave. Suite C, Livingston, NJ 07039, USA; corina.bot@gmail.com (C.B.); \\ Rodolfo.Haedo@naniontech.com (R.J.H.); ronald.knox@naniontech.com (R.K.) \\ * Correspondence: jcordeiro@mmri.edu; Tel.: +1-(315)-624-7480; Fax: +1-(315)-735-5648
}

\section{check for}

updates

Citation: Treat, J.A.; Pfeiffer, R.; Barajas-Martinez, H.; Goodrow, R.J.; Bot, C.; Haedo, R.J.; Knox, R.; Cordeiro, J.M. Overlap Arrhythmia Syndromes Resulting from Multiple Genetic Variations Studied in Human Induced Pluripotent Stem Cell-Derived Cardiomyocytes. Int. J. Mol. Sci. 2021, 22, 7108. https:// doi.org/10.3390/ijms22137108

Academic Editor: Ofer Binah

Received: 3 May 2021

Accepted: 24 June 2021

Published: 1 July 2021

Publisher's Note: MDPI stays neutra with regard to jurisdictional claims in published maps and institutional affiliations.

Copyright: (c) 2021 by the authors. Licensee MDPI, Basel, Switzerland. This article is an open access article distributed under the terms and conditions of the Creative Commons Attribution (CC BY) license (https:// creativecommons.org/licenses/by/ $4.0 /)$.
Abstract: Human induced pluripotent stem cell-derived cardiomyocytes (hiPSC-CMs) are used for genetic models of cardiac diseases. We report an arrhythmia syndrome consisting of Early Repolarization Syndrome (ERS) and Short QT Syndrome (SQTS). The index patient (MMRL1215) developed arrhythmia-mediated syncope after electrocution and was found to carry six mutations. Functional alterations resulting from these mutations were examined in patient-derived hiPSC-CMs. Electrophysiological recordings were made in hiPSC-CMs from MMRL1215 and healthy controls. ECG analysis of the index patient showed slurring of the QRS complex and QTc $=326 \mathrm{~ms}$. Action potential (AP) recordings from MMRL1215 myocytes showed slower spontaneous activity and AP duration was shorter. Field potential recordings from MMRL1215 hiPSC-CMs lack a "pseudo" QRS complex suggesting reduced inward current(s). Voltage clamp analysis of $\mathrm{I}_{\mathrm{Ca}}$ showed no difference in the magnitude of current. Measurements of $\mathrm{I}_{\mathrm{Na}}$ reveal a $60 \%$ reduction in $\mathrm{I}_{\mathrm{Na}}$ density in MMRL1215 hiPSC-CMs. Steady inactivation and recovery of $\mathrm{I}_{\mathrm{Na}}$ was unaffected. mRNA analysis revealed ANK2 and SCN5A are significantly reduced in hiPSC-CM derived from MMRL1215, consistent with electrophysiological recordings. The polygenic cause of ERS/SQTS phenotype is likely due to a loss of $\mathrm{I}_{\mathrm{Na}}$ due to a mutation in PKP2 coupled with and a gain of function in $\mathrm{I}_{\mathrm{K}, \mathrm{ATP}}$ due to a mutation in $A B C C$.

Keywords: action potentials; depolarization; electrophysiology; sodium current; stem cells

\section{Introduction}

Induced pluripotent stem cells derived from humans (hiPSCs) are utilized for investigations of cardiac genetic diseases affecting ion channels and/or structural proteins [1,2]. Using fibroblasts obtained from the patient, the fibroblasts can be de-differentiated into iPSCs and then directed to the cardiac lineage to allow systematic evaluation of the effects of these mutation(s) on ion channel function. Often the clinical phenotype observed in the patient is not due to a single mutation but may be the result of multiple genetic variations. Numerous cardiac diseases have been studied in hiPSC models and these models were able to capture the electrophysiological alterations observed in the clinic [3-5].

Many arrhythmias occur in the atria or ventricle and appear in the absence of structural defects. For example, short QT syndrome (SQTS) and early repolarization syndrome (ERS) are conditions linked to variations in ion channels [6-8]. SQTS is characterized by a QTc $<330 \mathrm{~ms}$ and as many as six different genes have been linked to SQTS [9]. ERS (sometimes referred to as J-wave syndrome [10]) typically appears as a slurring or notch in the ST segment and nine genes have been associated with this syndrome [11]. The QT 
interval is governed by the ventricular action potential duration which depends on the balance of currents during the repolarization phase of the action potential. In SQTS, a reduction in inward currents like $\mathrm{I}_{\mathrm{Ca}}$ or increases in outward repolarizing currents such as $\mathrm{I}_{\mathrm{Kr}}, \mathrm{I}_{\mathrm{Ks}}$ or $\mathrm{I}_{\mathrm{K} 1}$ leads to shortening of the action potential duration and QT interval [9,12]. In contrast, the slurring or notch in the ST segment observed in ERS patients suggests changes in phase one and phase two of the cardiac action potential secondary to an increase in $\mathrm{I}_{\text {to }}$ or decreases in $\mathrm{I}_{\mathrm{Na}}$ or $\mathrm{I}_{\mathrm{Ca}}$ [13].

Some cardiac channelopathies such as SQTS have shown a clear structure-function alteration due to a single mutation in one ion channel [14-16] whereas as other investigations show that multiple genetic variations may be involved [17,18]. Interestingly, many of these genetic variations are in proteins which are not cardiac ion channels. For example, GWAS analysis has found a high association between Brugada Syndrome $(\mathrm{BrS})$ and variations in the neuronal $\mathrm{Na}^{+}$channel $S C N 10 A$ [19] yet little to no Nav1.8 protein has been measured in cardiac tissue [20]. Similarly, variations in PXDNL which encodes a peroxidasin-like protein, [21] have been identified in $45 \%$ of patients with cardiac arrhythmia syndrome [18]. These studies further highlight the fact that multiple genes are involved in various cardiac arrhythmia syndromes.

In this study, we identified an individual that presented with an initial diagnosis of ERS and SQTS who exhibited multiple episodes of syncope following severe electrocution. Utilizing hiPSC- cardiomyocytes derived from the patient, medium throughput extracellular field potential analysis revealed a complete absence of 'pseudo' QRS complex suggesting a dramatic loss of inward currents responsible for initiating excitation. Interestingly, genetic analysis showed that the patient carried multiple variations in ion channel and structural proteins but none of these mutations were in the alpha subunit of genes responsible for $\mathrm{Na}^{+}$or $\mathrm{Ca}^{2+}$ channels. This disconnect was systematically evaluated using hiPSC-CMs derived from the patient.

\section{Results}

The index patient presented to the physician because of repeated episodes of syncope that developed several weeks after the patient was electrocuted while driving a forklift. Patient was a 27-year-old Caucasian male who was found unconscious after receiving the high voltage electrical shock. Analysis of the ECG revealed an ERS phenotype (Figure 1) coupled with a QT interval of 326 ms suggesting a secondary diagnosis of SQTS. Patient was inducible following programmed electrical stimulation with triple premature $400 / 240 / 200 / 20$ prior to procainimide challenge. After procainimide administration, the patient was very easily inducible which required cardioversion.

We performed NextGen sequencing of the index patient. Genetic analysis of the index patient revealed six heterozygous exonic mutations. Of the exonic mutations found, three were associated with ion channels and three of the mutations were predicted to be damaging by Sift analysis. The ANK2 gene was mutated from a $\mathrm{T}$ to A substitution at position 10901 in exon 41, resulting in an amino acid change from valine to aspartate at position 3634 (V1085D). The $A B C C 9$ gene was mutated from $C$ to $T$ at position 1987 in exon 14 resulting in an amino acid change from arginine to cysteine at position 663 (R663C). The $P K P 2$ gene was mutated from a $\mathrm{G}$ to $\mathrm{A}$ at position 76 in exon 1 resulting in an amino acid change from an aspartate to an asparagine at position 26 (D26N). Mutations and polymorphisms of the proband are shown in Table 1. 


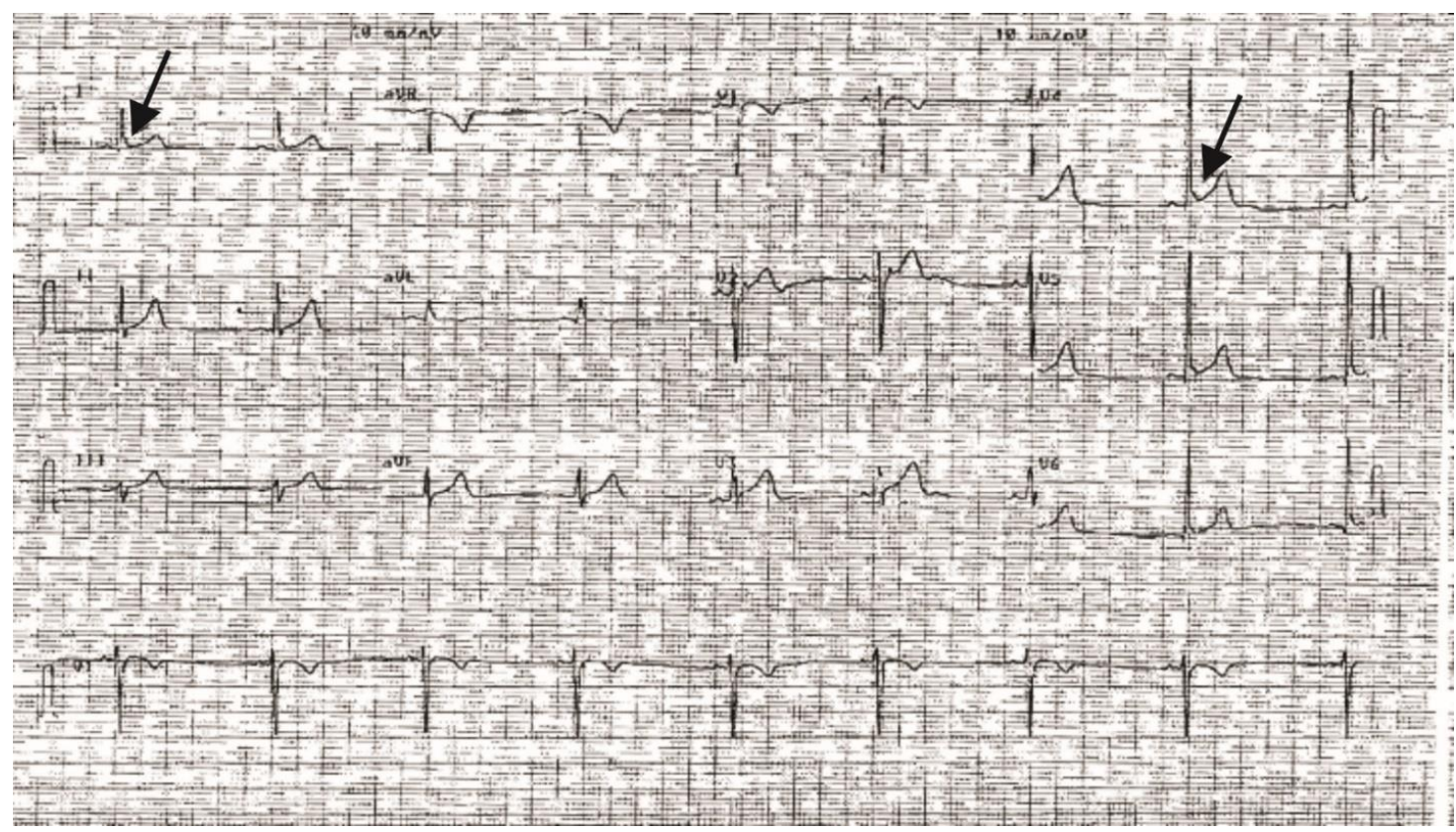

Figure 1. Representative ECG of MMRL1215 illustrating Early Repolarization Syndrome phenotype. A slurring of the QRS complex is apparent in multiple leads (denoted by the arrows). In addition, a QTc $=326$ ms was noted.

Table 1. MMRL1215 87 gene panel results.

\begin{tabular}{ccccccc}
\hline \# Locus & Gene & Exon & Protein & Coding & Sift & Dbsnp \\
\hline chr1:237947931 & RYR2 & 90 & $\begin{array}{c}\text { p.Arg4307Cys in Ryanodine } \\
\text { receptor 2 }\end{array}$ & c.12919C>T & Tolerated & rs200092869 \\
\hline chr4:114286207 & ANK2 & 41 & p.Val3634Asp in Ankyrin-B & c.10901T>A & Damaging & rs66785829 \\
\hline chr12:5154064 & KCNA5 & 1 & p.Ala251Thr in Kv1.5 & c.751G>A & Tolerated & rs12720442 \\
\hline chr12:22035732 & ABCC9 & 14 & $\begin{array}{c}\text { p.Arg663Cys in ATP Binding } \\
\text { Cassette C9 }\end{array}$ & c.1987C>T & Damaging & rs200349671 \\
\hline chr12:33049590 & PKP2 & 1 & p.Asp26Asn in Plakophilin 2 & c.76G >A & Damaging & rs143004808 \\
\hline chr19:615946 & HCN2 & 8 & $\begin{array}{c}\text { p.Pro715_Pro717del in } \\
\text { Cyclic Nucleotide channel 2 }\end{array}$ & c.2156_2164delCGCCGCCGC & rs879255365 \\
\hline
\end{tabular}

To determine the functional effects of these mutations/variations, we recorded extracellular field potentials (EFPs) from normal (WT) hiPSC-CMs and hiPSC-CMs derived from patient MMRL1215. Cells were plated on the microelectrode array at $\sim 75,000$ cells per plate and EFP recordings were made. Figure 2A shows the EFP recordings from 4 representative WT and MMRL1215 wells. The field potential recordings from WT hiPSC-CMs showed a 'pseudo' QRS complex and T wave, suggesting a normal activation-recovery cycle. In contrast, EFP recordings from MMRL1215 hiPSC-CMs showed no distinct QRS complex. In addition, the spontaneous beating frequency was slower in recordings obtained from MMRL1215 with a rate of $64.8 \pm 10.2 \mathrm{bpm}$ for WT and $48.0 \pm 10.8 \mathrm{bpm}$ for MMRL1215. The absence of a pronounced QRS complex coupled with the slower beating rate would suggest multiple ion channels are affected resulting in the complexed changes observed in the field potential recordings. We next recorded action potentials from WT and MMRL1215 hiPSC-CM monolayers (Figure 2B). MMRL1215 myocytes showed a slower beating rate and had a shorter APD compared to WT. The shorter APD may be the result of a gain of function mutations in KCNA5 and/or ABCC9 present in the patient (Table 1). The ABCC9 gene encodes the sulfonylurea receptor 2 (SUR2) protein which links with Kir6.1 and/or Kir6.2 to form a functional ATP-sensitive $\mathrm{K}^{+}$channel [22]. These channels are closed under 
normoxic conditions but activate when there is a decrease in intracellular ATP levels [23]. We wondered if the mutation in $A B C C 9$ altered the function of the channel resulting in these channels opening in under normoxic conditions in MMRL1215 myocytes. We next tested the effects of $10 \mu \mathrm{M}$ glybenclamide (an inhibitor of ATP-sensitive $\mathrm{K}^{+}$channels) on APs recorded from MMRL1215. Application of glybenclamide resulted in a prolongation of the APD, suggesting these channels are open under normoxic conditions. Tables 2 and 3 summarize the APs recorded from WT and MMRL1215 hiPSC-CM monolayers and the response to glibenclamide.
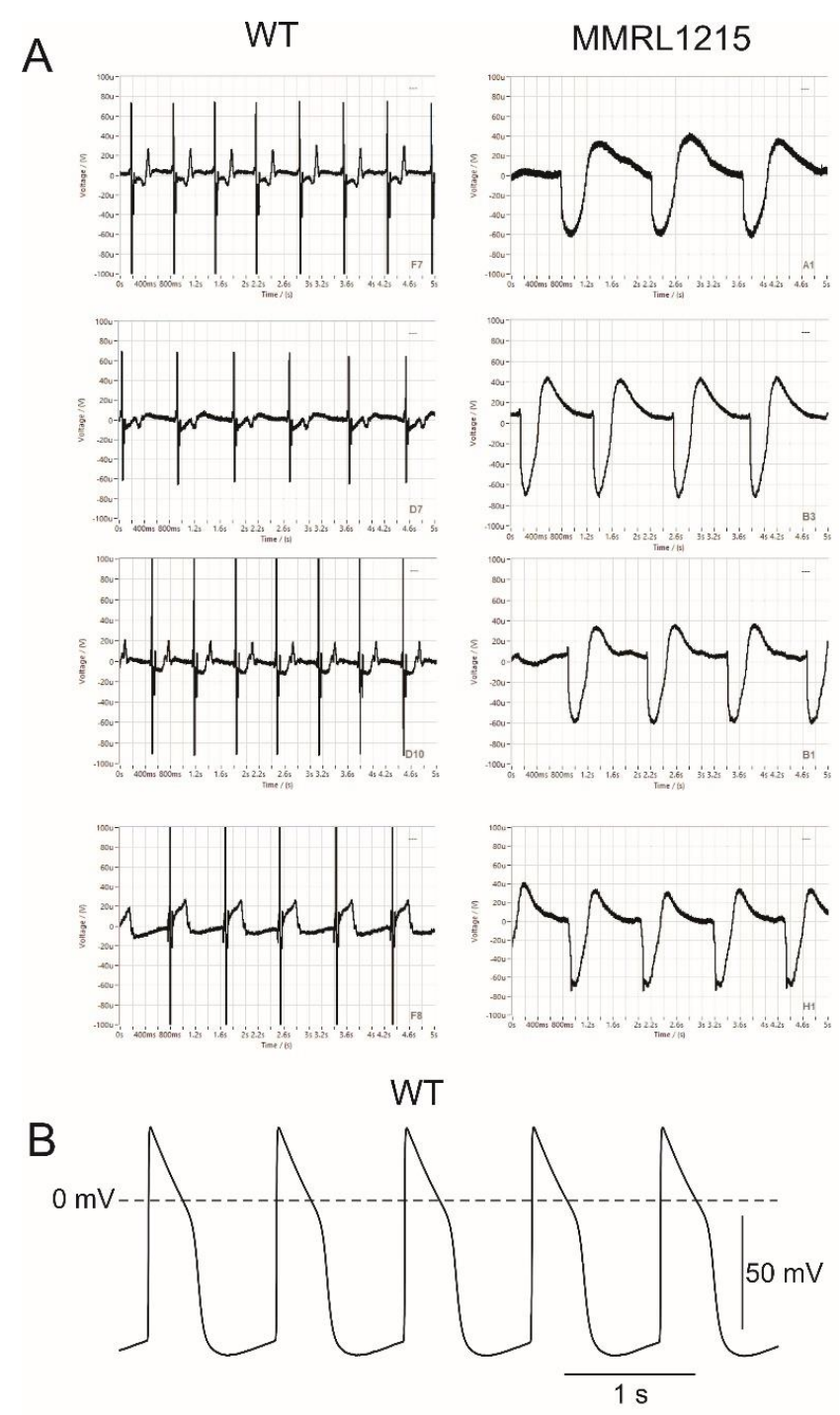

MMRL1215

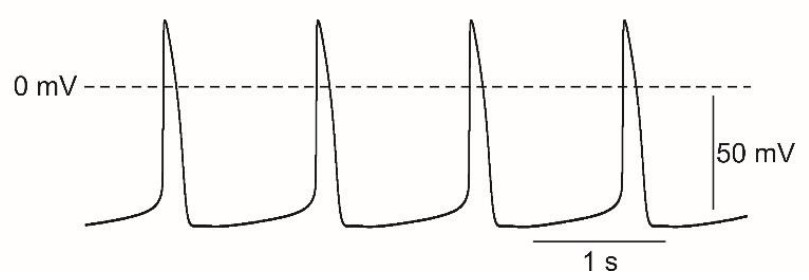

Figure 2. (A): Extracellular field potential (EFP) signals recorded in WT (left side) and MMRL1215 hiPSC-CMs (right side). Compared to WT hiPSC, myocytes derived from MMRL1215 showed a complete lack of a pseudo QRS complex, suggesting a major reduction in inward current(s). Panel (B): Action potential (AP) recordings obtained from WT and MMRL1215 monolayers. MMRL1215 hiPSC-CMs had a shorter action potential duration compared to WT. 
Table 2. Electrophysiological Parameters of WT and MMRL1215 hiPSC-CMs.

\begin{tabular}{|c|c|c|c|c|c|c|}
\hline & $\begin{array}{c}\text { Spontaneous } \\
\text { Cycle Length } \\
\text { (bpm) }\end{array}$ & $\begin{array}{c}\text { AP Amplitude } \\
(\mathrm{mV})\end{array}$ & APD50 (ms) & APD90 (ms) & $V \max (\mathrm{V} / \mathrm{s})$ & $\begin{array}{c}\text { Maximum } \\
\text { Diastolic } \\
\text { Potential (mV) }\end{array}$ \\
\hline CONTROL & $\begin{array}{c}61.9 \pm 4.2 \\
(n=14)\end{array}$ & $\begin{array}{c}105.7 \pm 4.4 \\
(n=14)\end{array}$ & $\begin{array}{c}380.6 \pm 31.9 \\
(n=14)\end{array}$ & $\begin{array}{c}456.2 \pm 29.4 \\
(n=14)\end{array}$ & $\begin{array}{c}26.9 \pm 2.8 \\
(n=14)\end{array}$ & $\begin{array}{c}-72.5 \pm 1.6 \\
(n=14)\end{array}$ \\
\hline MMRL1215 & $\begin{array}{l}48.7 \pm 4.0 \\
(n=16) *\end{array}$ & $\begin{array}{c}102 \pm 2.2 \\
(n=16)\end{array}$ & $\begin{array}{c}206.6 \pm 33.8 \\
(n=16) *\end{array}$ & $\begin{array}{c}267.5 \pm 38.6 \\
(n=16) *\end{array}$ & $\begin{array}{c}22.6 \pm 3.3 \\
(n=16)\end{array}$ & $\begin{array}{c}-71.9 \pm 1.4 \\
(n=16)\end{array}$ \\
\hline
\end{tabular}

* Significantly different from control $(p<0.05)$.

Table 3. Effect of Glybenclamide $(10 \mu \mathrm{M})$ on WT and MMRL1215 hiPSC-CM Electrophysiological Parameters.

\begin{tabular}{|c|c|c|c|c|c|c|}
\hline & $\begin{array}{l}\text { Spontaneous } \\
\text { Cycle Length } \\
\text { (bpm) }\end{array}$ & $\begin{array}{l}\text { AP Amplitude } \\
(\mathrm{mV})\end{array}$ & APD50 (ms) & APD90 (ms) & Vmax V/s) & $\begin{array}{c}\text { Maximum } \\
\text { Diastolic } \\
\text { Potential (mV) }\end{array}$ \\
\hline $\begin{array}{c}\text { MMRL1215 } \\
\text {-glybenclamide }\end{array}$ & $\begin{array}{c}43.3 \pm 4.8 \\
(n=6)\end{array}$ & $\begin{array}{c}100.2 \pm 5.0 \\
(n=6)\end{array}$ & $\begin{array}{c}240.9 \pm 42.8 \\
(n=6)\end{array}$ & $\begin{array}{c}295.7 \pm 44.4 \\
(n=6)\end{array}$ & $\begin{array}{c}33.4 \pm 10.9 \\
\quad(n=6)\end{array}$ & $\begin{array}{c}-67.1 \pm 2.8 \\
(n=6)\end{array}$ \\
\hline $\begin{array}{c}\text { MMRL1215 } \\
+ \text { glybenclamide }\end{array}$ & $\begin{array}{c}54.3 \pm 12.3 \\
\quad(n=6)\end{array}$ & $\begin{array}{c}91.3 \pm 10.4 \\
(n=6)\end{array}$ & $\begin{array}{c}262.5 \pm 33.8 \\
\quad(n=6)\end{array}$ & $\begin{array}{c}403.5 \pm 50.6 \\
\quad(n=6) *\end{array}$ & $\begin{aligned} 24.8 & \pm 10.5 \\
(n & =6)\end{aligned}$ & $\begin{array}{c}-61.9 \pm 5.7 \\
(n=6)\end{array}$ \\
\hline $\begin{array}{c}\text { WT } \\
\text {-glybenclamide }\end{array}$ & $\begin{array}{l}56.2 \pm 5.7 \\
(n=10)\end{array}$ & $\begin{array}{l}105.4 \pm 1.7 \\
(n=10)\end{array}$ & $\begin{array}{c}354.69 \pm 31.9 \\
(n=10)\end{array}$ & $\begin{array}{c}464.7 \pm 34.3 \\
\quad(n=10)\end{array}$ & $\begin{array}{c}29.4 \pm 3.4 \\
(n=10)\end{array}$ & $\begin{array}{c}-67.1 \pm 2.8 \\
(n=10)\end{array}$ \\
\hline $\begin{array}{c}\text { WT } \\
\text { +glybenclamide }\end{array}$ & $\begin{array}{c}51.4 \pm 9.1 \\
(n=10)\end{array}$ & $\begin{array}{c}105.5 \pm 3.5 \\
(n=10)\end{array}$ & $\begin{array}{c}316.3 \pm 35.0 \\
\quad(n=10)\end{array}$ & $\begin{array}{c}424.2 \pm 34.3 \\
\quad(n=10)\end{array}$ & $\begin{array}{c}31.0 \pm 4.8 \\
(n=10)\end{array}$ & $\begin{array}{c}-61.9 \pm 5.7 \\
(n=10)\end{array}$ \\
\hline
\end{tabular}

* Significantly different from -glybenclamide $(p<0.05)$.

Since EFP and AP recordings revealed differences in the electrophysiology, we speculated that $\mathrm{Ca}^{2+}$ transients would also be altered. Next we recorded calcium transients in WT hiPSC-CMs and hiPSC-CMs derived from patient MMRL1215 (Figure 3). The $\mathrm{Ca}^{2+}$ dye fluo-4 was loaded into hiPSC-CMs and $\mathrm{Ca}^{2+}$ transients were recorded from spontaneously beating cells. Compared to WT recordings, $\mathrm{Ca}^{2+}$ transients from patient 1215 showed lower fluorescence intensity (Table 4).

Table 4. Parameters of Calcium Transients from WT and MMRL 1215 hiPSC-CMs.

\begin{tabular}{ccccc}
\hline & $\begin{array}{c}\text { Spontaneous Cycle } \\
\text { Length }\end{array}$ & $\begin{array}{c}\text { Number with Regular } \\
\text { Spontaneous Cycle } \\
\text { Length }\end{array}$ & $\begin{array}{c}\text { \% with Regular } \\
\text { Spontaneous Cycle } \\
\text { Length }\end{array}$ & (F-Fo)/Fo \\
\hline CONTROL & $\begin{array}{c}1410.1 \pm 42.3 \mathrm{~ms} \\
(n=77)\end{array}$ & $77 / 78$ & $98.7 \%$ & $5.76 \pm 0.36(n=77)$ \\
\hline MMRL 1215 & $\begin{array}{c}1460.0 \pm 58.0 \mathrm{~ms} \\
(n=82)\end{array}$ & $82 / 86$ & $95.3 \%$ & $4.81 \pm 0.36(n=82) *$ \\
\hline
\end{tabular}

* Significantly different from control $(p<0.05)$. 


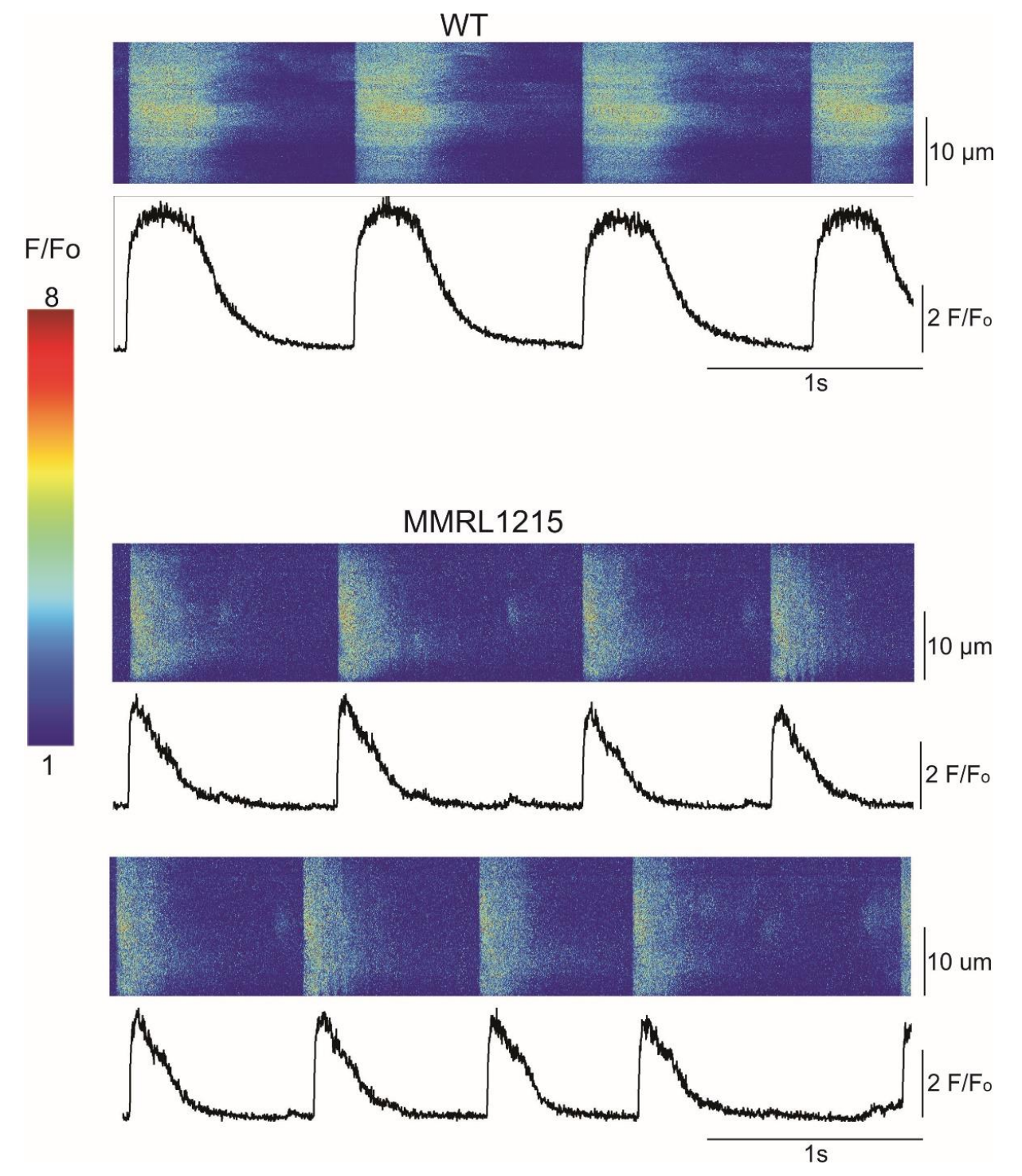

Figure 3. Line scans recorded from WT and MMRL1215 hiPSC-CMs showing spontaneous Ca ${ }^{2+}$ transients. Fluorescence intensity was much lower in MMRL 1215, and in some myocytes the spontaneous activity was episodic in nature.

The lower fluorescence intensity in 1215 hiPSC-CMs may indicate that there is less intracellular $\mathrm{Ca}^{2+}$ during an action potential secondary to a shorter AP duration [24]. Alternatively, the EFP recordings suggested that inward current(s) were altered and, therefore, the density of $\mathrm{I}_{\mathrm{Ca}}$ may be lower. We next performed patch clamp experiments to measure inward $\mathrm{I}_{\mathrm{Ca}}$ from WT and MMRL1215 hiPSC myocytes (Figure 4). I $\mathrm{Ca}$ was elicited by application of $300 \mathrm{~ms}$ step depolarizations from -40 to $+50 \mathrm{mV}$ and extended protocols were avoided to prevent current rundown. Peak $\mathrm{I}_{\mathrm{Ca}}$ density was $-18.8 \pm 2.5 \mathrm{pA} / \mathrm{pF}$ for WT and $-23.4 \pm 6.5 \mathrm{pA} / \mathrm{pF}$ for MMRL1215. The summarized data on $\mathrm{I}_{\mathrm{Ca}}$ current density in WT and MMRL1215 is shown in Figure 4C and no difference in current density was observed. 


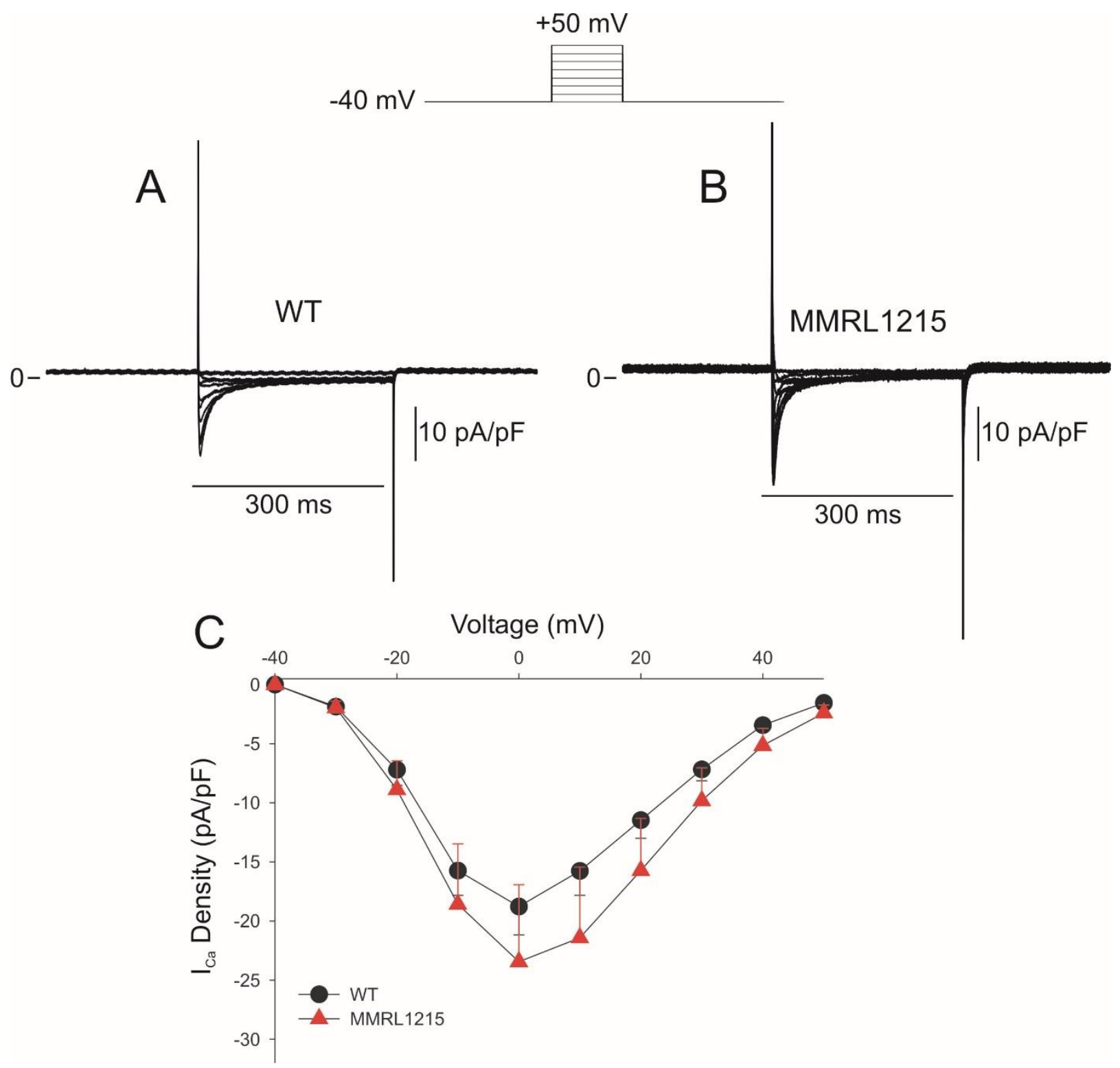

Figure 4. Representative traces showing $\mathrm{I}_{\mathrm{Ca}}$ recorded from WT $(n=11)$ and MMRL1215 $(n=9)(\mathbf{A}, \mathbf{B})$. Ca ${ }^{2+}$ currents were recorded during a $300 \mathrm{~ms}$ step depolarization from -40 to $+50 \mathrm{mV}$. (C) Current-voltage relationship for $\mathrm{I}_{\mathrm{Ca}}$.

As mentioned previously, the absence of a QRS complex in MMRL1215 hiPSC-CMs would suggest that inward currents are greatly reduced compared to WT. We next determined if inward $\mathrm{I}_{\mathrm{Na}}$ measured from hiPSC-CMs derived from the proband had a lower density compared to WT. Recordings were made from myocytes by manual patch clamp techniques in $40 \mathrm{mM}$ external $\mathrm{Na}^{+}$to ensure voltage control and representative $\mathrm{I}_{\mathrm{Na}}$ traces are shown (Figure 5A,B). Analysis of the current-voltage (I-V) relation showed that MMRL1215 had a decreased $\mathrm{I}_{\mathrm{Na}}$ density compared to WT myocytes (Figure 5C). Peak $\mathrm{I}_{\mathrm{Na}}$ density was $-80.6 \pm 10.49 \mathrm{pA} / \mathrm{pF}$ for WT and $-32.58 \pm 6.28 \mathrm{pA} / \mathrm{pF}$ for MMRL1215. We also determined if this reduction in peak $\mathrm{I}_{\mathrm{Na}}$ was due to changes in steady-state activation. Maximum conductance was obtained from the I-V curve and the ratio of current to the electromotive potential was calculated. A Boltzmann function was then fit to the data. Analysis of steady-state activation curves revealed half-activation voltages (V1/2) of $-33.13 \pm 0.39 \mathrm{mV}, \mathrm{k}=8.13 \pm 0.35$ for $\mathrm{WT}$ and $-37.61 \pm 0.41 \mathrm{mV}, \mathrm{k}=8.92 \pm 0.36$ for MMRL1215. 

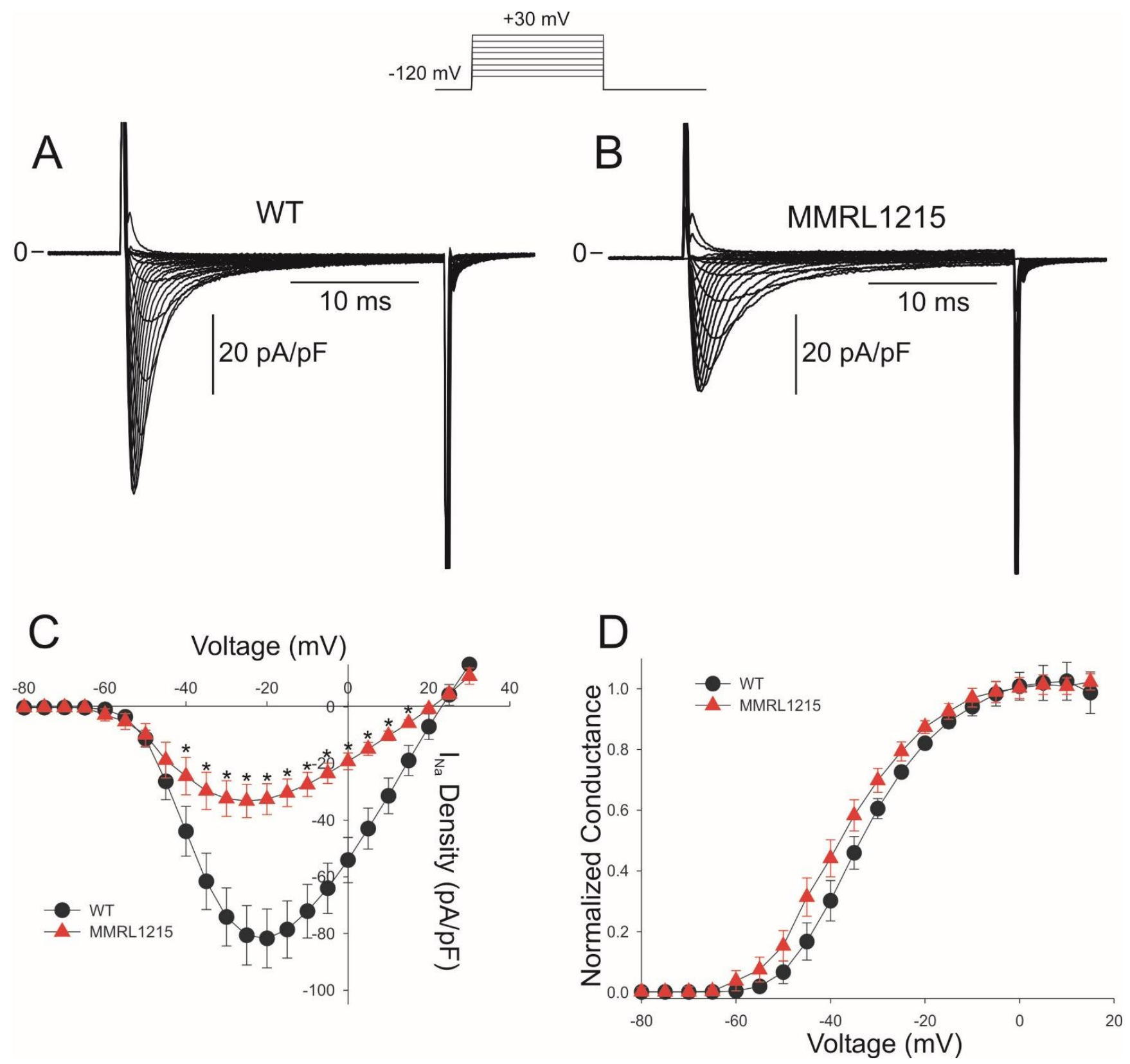

Figure 5. Representative whole cell $\mathrm{I}_{\mathrm{Na}}$ recordings from WT and MMRL1215 hiPSC-CMs (A,B). Current recordings were obtained at test potentials between -80 and $30 \mathrm{mV}$ (protocol at top of figure). (C): I-V relation for WT $(n=18)$ and MMRL1215 ( $n=25$ ) myocytes. (D): Steady-state activation curves for WT and MMRL1215 myocytes. Data were normalized and plotted against their test potential. * Statistically significant from WT, $p<0.05$.

The differences in $\mathrm{I}_{\mathrm{Na}}$ density between WT and MMRL1215 may be the result of differences in $\mathrm{Na}^{+}$channel availability at any given voltage. Steady-state inactivation was next evaluated in WT and MMRL1215 myocytes using a standard pre-pulse test pulse voltage clamp protocol. After application of a $500 \mathrm{~ms}$ pre-pulse, peak current was normalized to the maximum current and plotted as a function of the pre-pulse voltage. A Boltzmann function was then fit to the data. Figure 6 shows representative traces recorded from a WT (Panel A) and MMRL1215 myocyte (Panel B). The mid-inactivation potential was not significantly different in WT vs. MMRL1215 myocytes (Panel C) with $\mathrm{V} 1 / 2$ of $-82.3 \pm 0.21 \mathrm{mV}, \mathrm{k}=6.79 \pm 0.18$ for WT and $-81.1 \pm 0.23 \mathrm{mV}, \mathrm{k}=7.15 \pm 0.21$ for MMRL1215 suggesting decreased peak $\mathrm{I}_{\mathrm{Na}}$ in MMRL1215 was not due to differences in this parameter. 

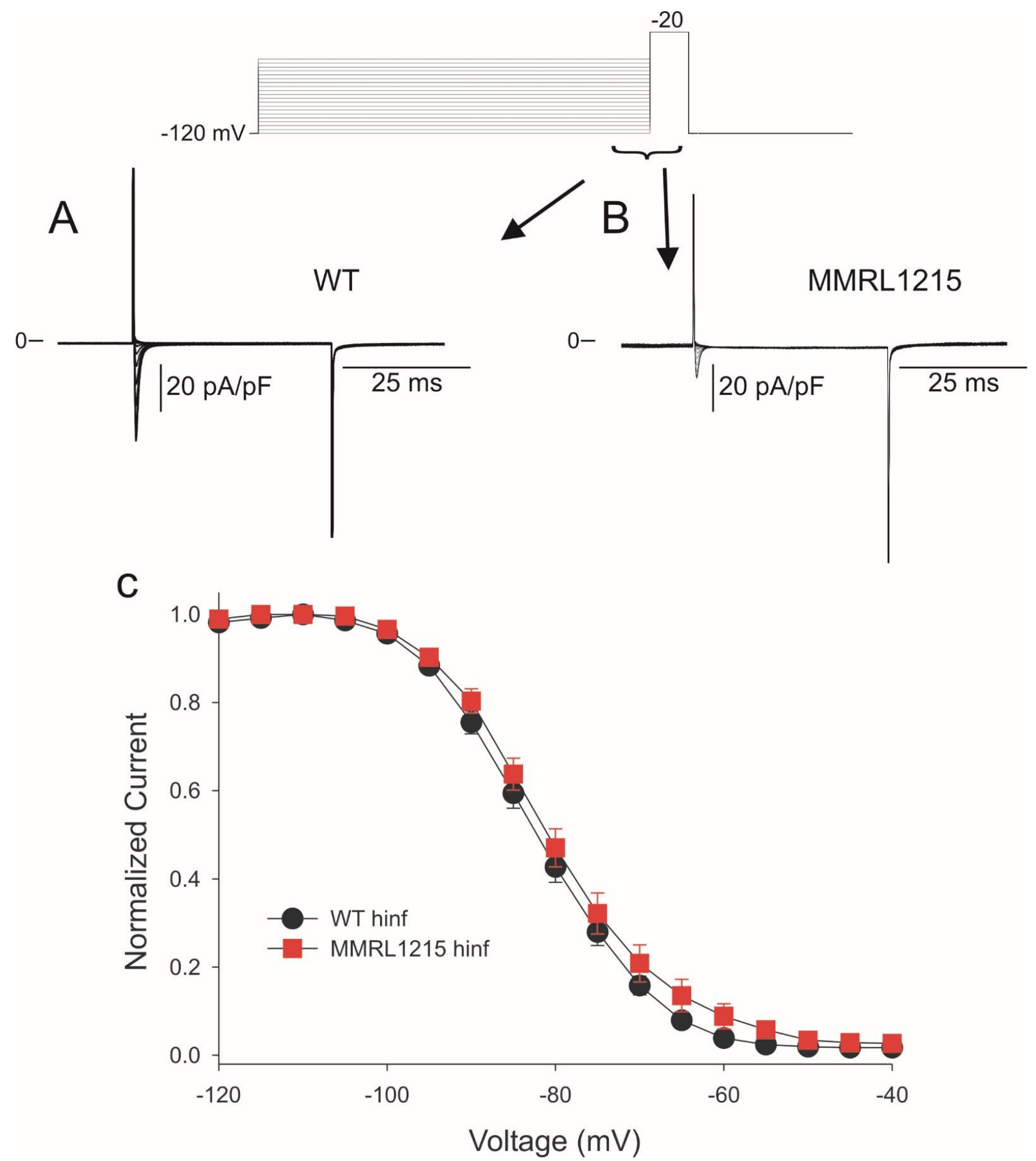

Figure 6. Representative steady-state inactivation recordings from WT and MMRL1215 myocytes (A,B) in response to the voltage clamp protocol (top of the figure). The steady state-inactivation relation for hiPSC-CMs (C) yielded similar mid-inactivation potential for WT $(n=25)$ and MMRL1215 $(n=29)$ cells.

In the next series of experiments, we determined if $\mathrm{I}_{\mathrm{Na}}$ recovery from inactivation was altered in WT and MMRL1215 myocytes. Recovery was determined using a double pulse protocol and was evaluated at holding potentials of $-120 \mathrm{mV}$ and $-100 \mathrm{mV}$ for both cell types. Figure 7 shows representative traces recorded from a WT (Panel A) and MMRL1215 myocyte (Panel B) at a holding potential of $-100 \mathrm{mV}$ (protocol shown at the top of the figure). Reactivation was much faster when $\mathrm{hp}=-120 \mathrm{mV}$ but was not significantly different between WT and MMRL1215. At $h p=-120 \mathrm{mV}$, both cell types 
exhibited a fast and slow phase of recovery with time constants as follows: $6.7 \pm 0.33 \mathrm{~ms}$ and $46.67 \pm 6.69 \mathrm{~ms}$ for WT myocytes and $4.97 \pm 1.10 \mathrm{~ms}$ and $35.18 \pm 7.49 \mathrm{~ms}$ for MMRL 1215 myocytes (Figure 7C). Similarly, at $\mathrm{hp}=-100 \mathrm{mV}$ the time constants for recovery were $18.5 \pm 2.0 \mathrm{~ms}$ and $64.78 \pm 10.78 \mathrm{~ms}$ for WT myocytes and $15.6 \pm 2.70 \mathrm{~ms}$ and $69.77 \pm 14.78 \mathrm{~ms}$ for MMRL 1215 myocytes (Figure 7D).
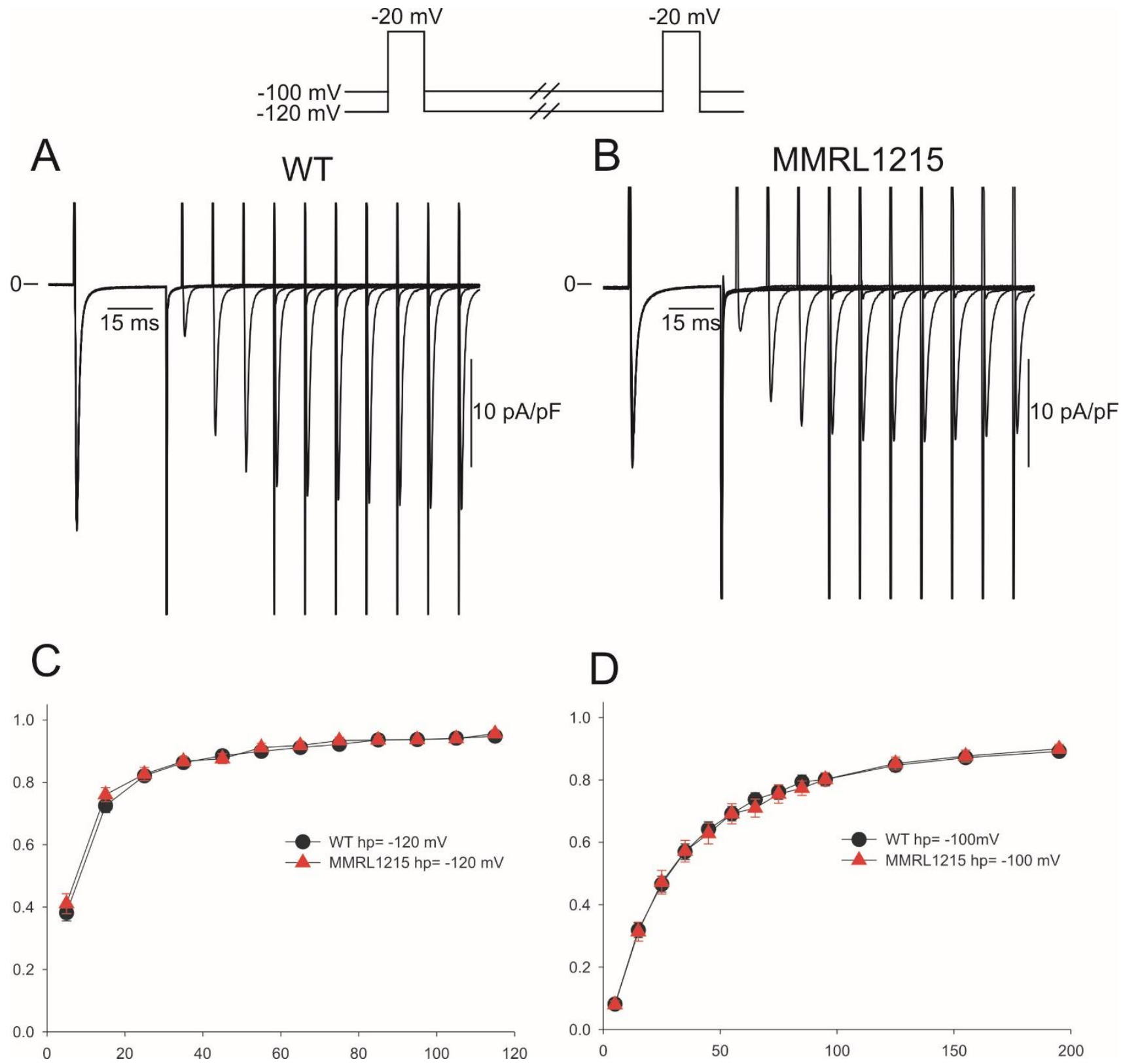

Figure 7. Representative recovery from inactivation traces recorded from WT and MMRL1215 myocytes (A,B). Recovery was measured using two identical voltage clamp steps to $-20 \mathrm{mV}$ from a holding potential of either $-120 \mathrm{mV}$ or $-100 \mathrm{mV}$ separated by selected time intervals. (C): Mean data showing recovery time-course of $\mathrm{I}_{\mathrm{Na}}$ recorded at $-120 \mathrm{mV}$ for WT $(n=24)$ and MMRL1215 $(n=26)$. (D): Recovery time-course of $\mathrm{I}_{\mathrm{Na}}$ recorded at $-100 \mathrm{mV}$ for WT $(n=16)$ and MMRL1215 $(n=19)$.

RNA expression of $\mathrm{Na}^{+}$channel $\alpha$-subunits was examined by RT-PCR analysis. Since both PKP2 and ANK2 have been shown to associate with Nav1.5, we also examined message levels of both to determine if the mutations altered the expression. Our results show the lower $\mathrm{I}_{\mathrm{Na}}$ density observed in hiPSC myocytes from MMRL1215 was paralleled by lower 
message of Nav1.5. Message levels of ANK2 were also significantly lower in MMRL1215 (Figure 8).

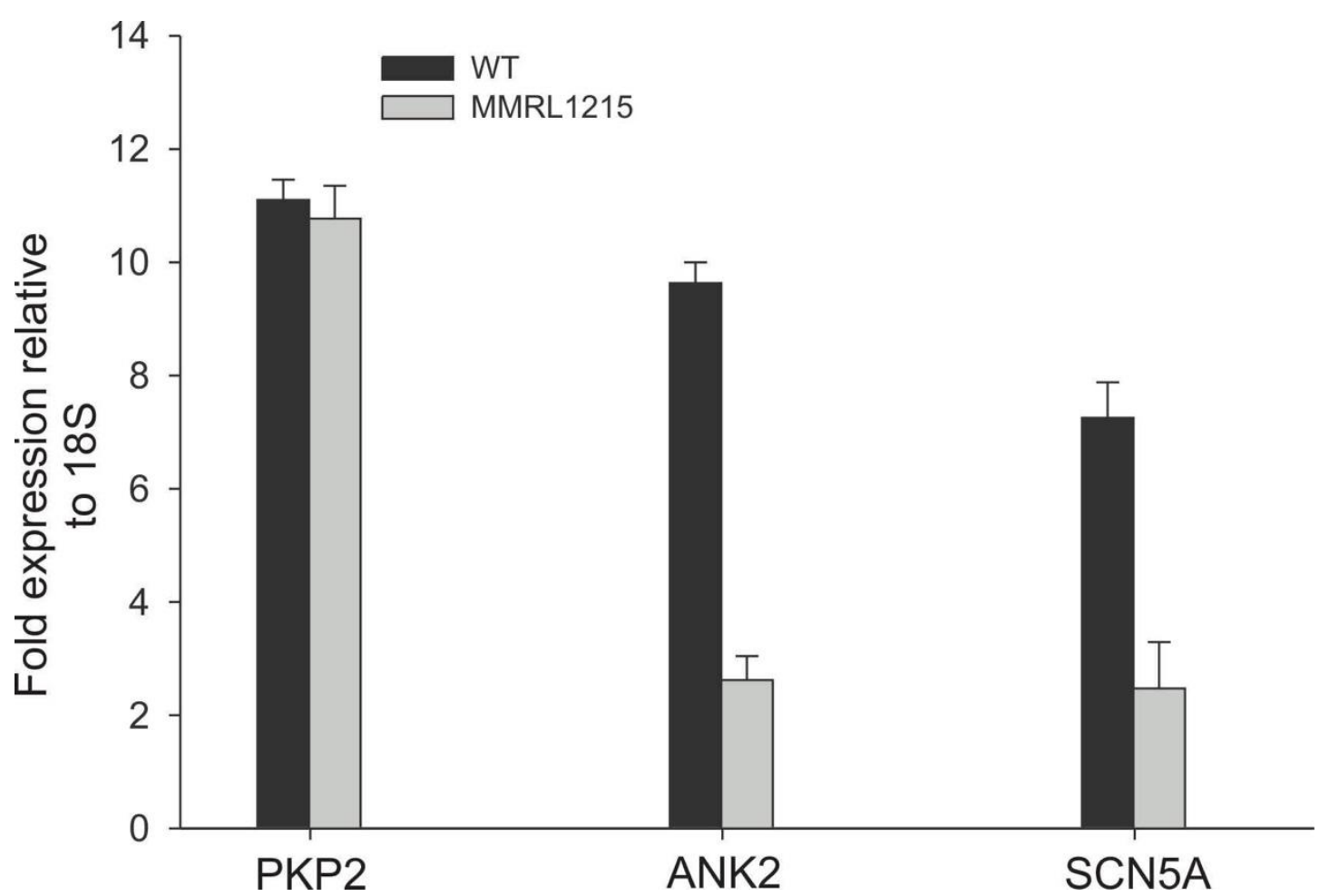

Figure 8. Expression profile of genes $P K P 2, A N K 2$ and $S C N 5 A$ obtained using real-time PCR.

\section{Discussion}

\subsection{Summary of Main Findings}

In the present study, we identified a patient who exhibited an ECG consistent with signs of early repolarization syndrome coupled with a QT interval of $326 \mathrm{~ms}$, suggesting a secondary diagnosis of short QT syndrome. Interestingly, these symptoms developed following high voltage electrocution. Genetic analysis of the patient showed the presence of multiple mutations in six genes of which only $A B C C 9$ was found to be associated with ERS [25]. However, none of the genetic variations have been associated with the secondary diagnosis of short QT syndrome. Using hiPSC-CMs derived from the patient, we found several abnormalities in EFP recordings, the $\mathrm{Ca}^{2+}$ transient magnitude, and a reduction in inward $\mathrm{Na}^{+}$current. In addition, the patient-derived hiPSC-CMs showed shorter APDs which could be reversed with glibenclamide, suggesting ATP-sensitive $\mathrm{K}^{+}$channels may be constitutively active in hiPSC-CMs from the patient. The reduction in $\mathrm{Na}^{+}$current coupled with a constitutively active ATP-sensitive $\mathrm{K}^{+}$channel may be the mechanism contributing to the mixed clinical phenotype.

The most striking observation in the study was the absence of a "pseudo" QRS complex in MMRL1215, suggesting a reduction in inward current(s). Voltage clamp analysis revealed a dramatic loss of $\mathrm{I}_{\mathrm{Na}}$ but no change in $\mathrm{I}_{\mathrm{Ca}}$. The loss in $\mathrm{I}_{\mathrm{Na}}$ occurred even though no mutation in SCN5A was detected. Previous studies have demonstrated that mutations in ANK2 and PKP2 have been associated with ion channel dysfunction leading to cardiac arrhythmias. Mutations in ANK2 are responsible for Long QT syndrome but these effects appear to be independent of any association with Nav1.5 [26]. Indeed, confocal analyses of WT and ankyrin-B-null mice ventricular myocytes revealed no difference in $\mathrm{Na}_{\mathrm{v}} 1.5$ immunolocalization suggesting no functional association of ankyrin-B and Nav1.5 [27]. Mutations in PKP2 have been associated with a loss of $\mathrm{I}_{\mathrm{Na}}$ resulting in $\mathrm{BrS}$ in a subset of patients. When BrS-associated mutation D26N in PKP2 was transiently transfected into 
HL-1 cells, a reduction in $\mathrm{I}_{\mathrm{Na}}$ by about $65 \%$ was noted [28]. Interestingly, our index patient (MMRL1215) carried the same D26N mutation in PKP2. Using hiPSC myocytes derived from the patient, we saw about a $60 \%$ reduction in $\mathrm{I}_{\mathrm{Na}}$, strongly suggesting the loss of $\mathrm{I}_{\mathrm{Na}}$ by $\mathrm{D} 26 \mathrm{~N}$ is responsible for primary diagnosis of ERS.

Interestingly, this patient carried a number of genetic variations, but the clinical symptoms did not manifest until the patient was severely electrocuted. The mechanism behind this manifestation remains unclear. Previous investigations from our group have shown a similar scenario in the situation of acute myocardial infarction [29]. Results from those studies showed that the index patient carried a SCN5A mutation which remained subclinical, but expressed clinically after the patient had an acute myocardial infarction $[29,30]$. Upon recovery from the MI, multiple arrhythmias were observed suggesting that physiological stressors can unmask certain arrhythmias. The presence of several genetic variations may increase the propensity for developing arrhythmias. In the present study, the physiological stressor was electrocution which resulted in unmasking of the ERS/SQTS phenotype in this patient. In a retrospective study, high voltage electrocution has been shown to unmask or precipitate several cardiac arrhythmias which persisted for some time after the initial event [31]; the presence of several variations/mutations may increase the susceptibility of developing arrhythmias.

Numerous studies have modelled complex arrhythmia syndromes in hiPSC-CMs but with variable results. This variability has been attributed to many factors such as the methodology used to differentiate the hiPSC into the cardiac lineage as well as the maturity of pluripotent hiPSC-CMs. Compared to adult ventricular cells, hiPSC-CMs are deficient in several currents such as $I_{K 1}$ and $I_{t o}$ [32,33]. Despite these deficiencies, functional analysis of the patient-derived hiPSC-CMs in this study were dramatically different compared WT myocytes suggesting that MMRL1215 hiPSC-CMs were able to recapitulate this complexed ECG phenotype (such as ERS/SQTS).

The appearance of ERS is likely the result of a decrease in depolarizing inward $\mathrm{I}_{\mathrm{Na}}$ during the early parts of the cardiac action potential. Alternatively, an increase in outward currents has been linked to the manifestation of ERS and SQTS [11]. The results of our study in hiPSC-CMs demonstrate that both mechanisms play a role. EFP recordings suggested a loss of inward current(s) and voltage clamp recordings confirmed $\mathrm{I}_{\mathrm{Na}}$ was reduced. The loss of $\mathrm{I}_{\mathrm{Na}}$ was dramatic although no mutation in SCN5A was noted. Previous studies have demonstrated that mutations in PKP2 result in a loss of $\mathrm{I}_{\mathrm{Na}}$ which is likely the situation in our patient. Similarly, the appearance of SQTS has been linked to mutations resulting in increased outward $\mathrm{K}^{+}$currents and AP analysis confirmed that $\mathrm{I}_{\mathrm{K}, \mathrm{ATP}}$ appears to be constitutively active in MMRL1251 hiPSC-CMs. The presence of all variations (Table 1) may have an additive effect leading to the reduction of $\mathrm{I}_{\mathrm{Na}}$ and an increase in $\mathrm{I}_{\mathrm{K}, \mathrm{ATP}}$ resulting in the clinical phenotype.

\subsection{Conclusions}

Many ventricular arrhythmia syndromes have been linked to mutations in $S C N 5 A$, $P K P 2, A N K 2$, and $A B C C 9$. Interestingly, the index patient carried mutations/variations in these genes resulting in an overlap syndrome with characteristics of both ERS and SQTS. Although the patient carried six genetic variations of which three were predicted to be damaging by Sift analysis, the development of the clinical phenotype was not observed until the patient received a high voltage shock. Using hiPSC myocytes derived from the patient, we show clear functional alterations in a number of parameters such as altered EFP recordings, reduced $\mathrm{I}_{\mathrm{Na}}$ density and altered action potential duration when compared to normal hiPSC myocytes. Our study shows that multiple genetic mutations can alter physiologic function and demonstrate the effectiveness of patient derived hIPSC myocytes to systematically examine the phenotypic changes. 


\subsection{Limitations of the Study}

All current recordings from the hiPSC-CMs were made after 21 days after plating. However, it is not certain hiPSC-CM kept in culture for longer time periods would result in changes such as a larger $\mathrm{I}_{\mathrm{Na}}$ density or more mature calcium induced calcium release machinery such as development of t-tubules. Previous studies have shown that the biophysical and molecular characteristics of $\mathrm{I}_{\mathrm{Na}}$ vary in adult ventricular, atrial and SA nodal myocytes [34-36]. Since hiPSC myocytes have been described as having nodal, atrial and ventricular phenotypes based on action potential morphology, we surmised that the 3 cell types may also show different $\mathrm{I}_{\mathrm{Na}}$ densities.

\section{Methods}

\subsection{Subjects}

IRB approval and informed consent was obtained from the patient included in this study. The proband was identified following repeated episodes of syncope and dizziness following electrocution.

\subsection{Next Generation Sequencing}

An Ion Torrent Personal Genome Machine (PGM) was utilized to perform high throughput sequencing (HTS) which enabled the sequencing of 87 candidate genes at a time, a previously described [18]. These candidate genes encode ion channels and other proteins including pumps, exchangers, calcium handling proteins, gap junctional proteins, and structural proteins. They were selected based on their relative expression in human neuronal and cardiac tissue and their functional roles in generating action potentials and altering excitability.

The Ion Torrent PGM (Life Technologies, Carlsbad, CA, USA) sequenced genomic DNA fragments generated through the use of Custom Ion Ampliseq 2.0 (Life Technologies, Carlsbad, CA, USA). The Coding Exons as well as intron borders for our 87 genes of interest from human genomic DNA were amplified through a massive multiplex PCR approach. DNA libraries were prepared by attaching adapters to these fragments, as well as a unique molecular barcode for each sample. Library quality was assessed using the Qubit 2.0 Fluorometer and the dsDNA HS Assay (Life Technologies, Carlsbad, CA, USA). An Ion Chef automation system then performed emulsion PCR, enrichment, and chip loading, followed by direct sequencing with the Ion Torrent PGM.

\subsection{Mutation Confirmation}

All rare variations and mutations uncovered were confirmed using gold standard Sanger sequencing. PCR products were purified with a commercial enzyme (ExoSAP- IT, USB, Cleveland, OH, USA) and directly sequenced from both directions using Big Dye Terminator 3.1 chemistry on an Applied Biosystems 3730 DNA Analyzer (Life Technologies, Carlsbad, CA, USA).

\subsection{Bioinformatics Analysis}

The Ion Torrent Suite software was used to map the sequencing reads to the DNA reference sequence [hg19] and identify variants through the VariantCaller plugin as well as the IonReporter analysis tool. Run Quality was assessed using the Coverage Analysis plugin which reports average depth of coverage, uniformity of coverage, and percent on target as well as other metrics. IonReporter compares all variations identified against NCBI's dbSNP to rule out common SNP's, as well as the 1000 genomes project and Exome Sequencing Project (ESP) to get published frequencies. Variants of interest were then flagged for verification through Sanger Sequencing. Mutations and rare variants were analyzed using several pathogenicity prediction tools such as PolyPhen2, SIFT and Grantham. When available, family members were sequenced for these mutations and rare variants to analyze the penetrance and establish a genotype-phenotype correlation. 


\section{5. hiPSC-CM Generation}

Human WT iPSC (WiCell, Madison, WI, USA), passage 18-25, were maintained on growth factor-reduced Matrigel (Corning Corp., Corning, NY, USA.) coated plates in E8 medium (Gibco, Gaithersburg, MD, USA) with E8 supplement (Gibco, Gaithersburg, MD, USA). Patient derived human iPS cells were reprogrammed from fibroblasts with Oct4, Sox2, Lin28, and Nanog. A directed differentiation protocol to derive cardiomyocytes using serum-free, chemically defined media supplemented with CHIR99021, IWP2, Activin A, and KY0211 in stage specific manner, as previously described [37]. This protocol yielded contractile clusters by days 9 to 12 post-differentiation. Monolayers ranging between 20-50 days of maturity were plated on matrigel coated dishes and maintained with RPMI B27+ until use.

\subsection{Extracellular Field Potential and Impedance Recordings}

Human iPSC-CMs were seeded and maintained on CardioExcyte 96 (Nanion Technologies, Livingston, NJ, USA) 96 well sensor plates. Extracellular field potential recordings were recorded with the CardioExcyte 96 when cells began to spontaneously contract (about 5-8 days after initial plating).

\subsection{Electrophysiological Recordings}

Voltage clamp recordings were made using patch pipettes fabricated from borosilicate glass capillaries (1.5 mm O.D., Fisher Scientific, Pittsburg, PA, USA). The pipettes were pulled using a gravity puller (Model PP-830, Narashige Corp., Amityville, NY, USA) and filled with pipette solution of the following composition $(\mathrm{mM})$ : For $\mathrm{I}_{\mathrm{Ca}}$ recordings in hiPSCCMs, the external solution contained (in $\mathrm{mM}$ ): $\mathrm{NaCl} 140, \mathrm{KCl} 5.4, \mathrm{MgCl}_{2}$ 1, HEPES 10, D-Glucose 10, and $\mathrm{CaCl}_{2} 1.8, \mathrm{pH}$ was adjusted to 7.4 with $\mathrm{NaOH}$. The $\mathrm{I}_{\mathrm{Ca}}$ patch pipette contained (in mM) $\mathrm{CsCl} 120, \mathrm{MgCl}_{2}$ 1.0, EGTA 10, MgATP 5, HEPES 5, and $\mathrm{CaCl}_{2} 1.8$, $\mathrm{pH}=7.2$ with $\mathrm{CsOH}$ [38]. For $\mathrm{I}_{\mathrm{Na}}$ recordings in hiPSC-CMs, the external solution contained (in mM): N Methyl D-Glucamine 105, $\mathrm{NaCl} 40, \mathrm{CaCl}_{2} 2.0, \mathrm{MgCl}_{2}$ 1.0, glucose 10, HEPES free acid 10, $\mathrm{CdCl}_{2} 0.3, \mathrm{pH}$ adjusted to 7.4 with $\mathrm{NaOH} / \mathrm{HCl}$. The pipette solution contained (in $\mathrm{mM}) \mathrm{NaCl} 15, \mathrm{CsF} 120, \mathrm{MgCl}_{2}$ 1, $\mathrm{KCl}$ 5, HEPES 10, $\mathrm{Na}_{2}$ ATP 4, and EGTA 10, pH adjusted to 7.2 with $\mathrm{CsOH}[39,40]$. Current signals were recorded using a MultiClamp 700A amplifier (Molecular Devices, San Jose, CA, USA) and series resistance errors were reduced by about $60-70 \%$ with electronic compensation. Signals were acquired at $20-50 \mathrm{kHz}$ (Digidata 1322 , Molecular Devices, San Jose, CA, USA) and analyzed with a microcomputer running pClamp 9 software (Molecular Devices, San Jose, CA, USA). All patch recordings were made at $37^{\circ} \mathrm{C}$ with the exception of $\mathrm{I}_{\mathrm{Na}}$ which was performed at room temperature.

Sharp microelectrodes (40-60 M $\Omega$ ) filled with $2.7 \mathrm{M} \mathrm{KCl}$ were used to record APs from spontaneously beating monolayers, as previously described [40]. Monolayers were superfused with HEPES-Tyrode's solution of the following composition (in $\mathrm{mM}$ ): $\mathrm{NaCl}$ $140, \mathrm{KCl} 5.4, \mathrm{MgCl}_{2}$ 1, HEPES 10, D-Glucose 10, and $\mathrm{CaCl}_{2} 1.8, \mathrm{pH}$ was adjusted to 7.4 with $\mathrm{NaOH}$. The microelectrodes were connected to an MultiClamp 700B amplifier (Molecular Devices, San Jose, CA, USA) operating in current clamp mode. All signals were digitized (sampling rate $=50 \mathrm{kHz}$ ), stored on a computer and analyzed using pClamp9 acquisition suite (Molecular Devices, San Jose, CA, USA).

\subsection{Fluorescence Imaging}

Confocal $\mathrm{Ca}^{2+}$ imaging experiments were performed with an Olympus Fluoview laser-scanning confocal microscope (Olympus Life Science, Center Valley, PA, USA) as previously described [18,41]. Fluo 4-AM [dissolved in 20\% F-127 pluronic in dimethyl sulfoxide (DMSO), final concentration $15 \mu \mathrm{M}$ ] was added to hiPSC-CMs and incubated for $20 \mathrm{~min}$ at room temperature. Fluo-4 loaded hiPSC-CMs were placed in a perfusion chamber and excited at $488 \mathrm{~nm}$ using an argon laser, and fluorescence emission was detected via a 520-nm band-pass filter and photomultiplier tube. Confocal images were acquired with the Fluoview acquisition software program and spontaneous activity was recorded on a 
personal computer for later analysis. Images acquired with Fluoview acquisition software were analyzed with ImageJ and Fluoview analysis software (Olympus Life Science, Center Valley, PA, USA).

\subsection{RNA Isolation and Quantitative Real-Time PCR}

Quantitative real-time PCR was performed as described previously [37]. RNA was isolated from hiPSC cardiomyocytes 15 days after plating using the TRiZOL reagent (Life Technologies, Carlsbad, CA, USA), according to the manufacturer's protocols. A NanoDrop ${ }^{\circledR}$ spectrophotometer (Thermo Fisher, Wilmington, DE, USA) was used to quantify RNA. Superscript ${ }^{\mathrm{TM}}$ III Reverse Transcriptase kit (Life Technologies, Carlsbad, CA, USA) approach was used to synthesize cDNA from 1-5 $\mu \mathrm{g}$ of RNA. Standard curves were generated to calculate the efficiency of the probe.

TaqMan Probe sets:

SCN5A-Hs00165693_m1 (Life Technologies)

PKP2-Hs00428040 m1 (Life Technologies)

ANK2—00153998 m1 (Life Technologies)

18s-Hs03003631_g1 (Life Technologies)

All no-template control wells were negative in all PCR runs. The mRNA levels were referenced to $18 \mathrm{~s}$ and the $\Delta \Delta \mathrm{Ct}$ relative quantification method was used [19].

\subsection{Statistical Analysis}

All data are presented as Mean \pm SEM. Statistical comparisons were made using ANOVA followed by a Student-Newman-Kuels, or Student's $t$-test, as appropriate. Significance was determined at $p<0.05$.

Author Contributions: J.A.T. and J.M.C. contributed to the concepts and design of the study. J.A.T., R.J.G., R.P., H.B.-M., C.B., R.J.H., R.K. and J.M.C. participated in experimental design, data collection and data analysis. J.M.C. drafted the initial versions of the manuscript. All investigators contributed to drafting and critical revision of the article. All authors have read and agreed to the published version of the manuscript.

Funding: This study was supported by the Free and Accepted Masons of New York, Florida, Massachusetts, Connecticut, Maryland, Wisconsin, Washington, and Rhode Island (to J.M.C.).

Institutional Review Board Statement: The study was conducted according to the guidelines of the Declaration of Helsinki and approved by the Institutional Review Board of Masonic Medical Research Institute (MMRL 003-Molecular Genetic Basis for Inherited Cardiac Arrhythmias and Cardiomyopathies IRB\#001. Approval date: 5 November 2020).

Informed Consent Statement: Informed consent was obtained from all subjects involved in the study.

Data Availability Statement: The data presented in this study are available on request from the corresponding author at jcordeiro@mmri.edu. The data are not publicly available due to Masonic Medical Research Institute confidentiality policies.

Conflicts of Interest: The authors report no relationships that can be construed as a conflict of interest.

\section{References}

1. Takahashi, K.; Tanabe, K.; Ohnuki, M.; Narita, M.; Ichisaka, T.; Tomoda, K.; Yamanaka, S. Induction of Pluripotent Stem Cells from Adult Human Fibroblasts by Defined Factors. Cell 2007, 131, 861-872. [CrossRef] [PubMed]

2. Wu, J.C.; Garg, P.; Yoshida, Y.; Yamanaka, S.; Gepstein, L.; Hulot, J.-S.; Knollmann, B.C.; Schwartz, P.J. Towards Precision Medicine with Human iPSCs for Cardiac Channelopathies. Circ. Res. 2019, 125, 653-658. [CrossRef] [PubMed]

3. Terrenoire, C.; Wang, K.; Tung, K.W.C.; Chung, W.K.; Pass, R.H.; Lu, J.T.; Jean, J.-C.; Omari, A.; Sampson, K.J.; Kotton, D.; et al. Induced pluripotent stem cells used to reveal drug actions in a long QT syndrome family with complex genetics. J. Gen. Physiol. 2012, 141, 61-72. [CrossRef] 
4. $\quad$ El-Battrawy, I.; Lan, H.; Cyganek, L.; Zhao, Z.; Li, X.; Buljubasic, F.; Lang, S.; Yücel, G.; Sattler, K.; Zimmermann, W.; et al. Modeling Short QT Syndrome Using Human-Induced Pluripotent Stem Cell-Derived Cardiomyocytes. J. Am. Heart Assoc. 2018, 7. [CrossRef] [PubMed]

5. Sendfeld, F.; Selga, E.; Scornik, F.S.; Pérez, G.J.; Mills, N.L.; Brugada, R. Experimental Models of Brugada syndrome. Int. J. Mol. Sci. 2019, 20, 2123. [CrossRef] [PubMed]

6. Schwartz, P.J.; Priori, S.G.; Dumaine, R.; Napolitano, C.; Antzelevitch, C.; Stramba-Badiale, M.; Richard, T.A.; Berti, M.R.; Bloise, R. A Molecular Link between the Sudden Infant Death Syndrome and the Long-QT Syndrome. N. Engl. J. Med. 2000, 343, 262-267. [CrossRef]

7. Burashnikov, E.; Pfeiffer, R.; Barajas-Martinez, H.; Delpón, E.; Hu, D.; Desai, M.; Borggrefe, M.; Häissaguerre, M.; Kanter, R.; Pollevick, G.D.; et al. Mutations in the cardiac L-type calcium channel associated J wave sydnrome and sudden cardiac death. Heart Rhythm 2010, 7, 1872-1882. [CrossRef]

8. Hu, D.; Barajas-Martínez, H.; Terzic, A.; Park, S.; Pfeiffer, R.; Burashnikov, E.; Wu, Y.; Borggrefe, M.; Veltmann, C.; Schimpf, R.; et al. ABCC9 is a novel Brugada and early repolarization syndrome susceptibility gene. Int. J. Cardiol. 2014, 171, 431-442. [CrossRef]

9. Campuzano, O.; Fernandez-Falgueras, A.; Lemus, X.; Sarquella-Brugada, G.; Cesar, S.; Coll, M.; Mates, J.; Arbelo, E.; Jordà, P.; Perez-Serra, A.; et al. Short QT Syndrome: A Comprehensive Genetic Interpretation and Clinical Translation of Rare Variants. J. Clin. Med. 2019, 8, 1035. [CrossRef]

10. Antzelevitch, C. Genetic, Molecular and Cellular Mechanisms Underlying the J Wave Syndromes. Circ. J. 2012, 76, 1054-1065. [CrossRef]

11. Bourier, F.; Denis, A.; Cheniti, G.; Lam, A.; Vlachos, K.; Takigawa, M.; Kitamura, T.; Frontera, A.; Duchateau, J.; Pambrun, T.; et al. Early Repolarization Syndrome: Diagnostic and Therapeutic Approach. Front. Cardiovasc. Med. 2018, 5. [CrossRef]

12. Brugada, R.; Hong, K.; Cordeiro, J.; Dumaine, R. Short QT syndrome. Can. Med. Assoc. J. 2005, 173, 1349-1354. [CrossRef]

13. Koncz, I.; Gurabi, Z.; Patocskai, B.; Panama, B.K.; Szél, T.; Hu, D.; Barajas-Martínez, H.; Antzelevitch, C. Mechanisms underlying the development of the electrocardiographic and arrhythmic manifestations of early repolarization syndrome. J. Mol. Cell. Cardiol. 2014, 68, 20-28. [CrossRef] [PubMed]

14. Brugada, R.; Hong, K.; Dumaine, R.; Cordeiro, J.; Gaita, F.; Borggrefe, M.; Menendez, T.M.; Brugada, J.; Pollevick, G.D.; Wolpert, C.; et al. Sudden Death Associated With Short-QT Syndrome Linked to Mutations in HERG. Circulation 2004, 109, 30-35. [CrossRef] [PubMed]

15. Bellocq, C.; Van Ginneken, A.C.G.; Bezzina, C.R.; Alders, M.; Escande, D.; Mannens, M.M.A.M.; Baró, I.; Wilde, A.A.M. Mutation in the KCNQ1 Gene Leading to the Short QT-Interval Syndrome. Circulation 2004, 109, 2394-2397. [CrossRef] [PubMed]

16. Priori, S.G.; Pandit, S.V.; Rivolta, I.; Berenfeld, O.; Ronchetti, E.; Dhamoon, A.; Napolitano, C.; Anumonwo, J.; di Barletta, M.R.; Gudapakkam, S.; et al. A Novel Form of Short QT Syndrome (SQT3) Is Caused by a Mutation in the KCNJ2 Gene. Circ. Res. 2005, 96, 800-807. [CrossRef]

17. Cerrone, M.; Remme, C.A.; Tadros, R.; Bezzina, C.R.; Delmar, M. Beyond the One Gene-One Disease Paradigm: Complex Genetics and Pleiotropy in Inheritable Cardiac Disorders. Circulation 2019, 140, 595-610. [CrossRef] [PubMed]

18. Barajas-Martinez, H.; Smith, M.; Hu, D.; Goodrow, R.J.; Puleo, C.; Hasdemir, C.; Antzelevitch, C.; Pfeiffer, R.; Treat, J.A.; Cordeiro, J.M. Susceptibility to Ventricular Arrhythmias Resulting from Mutations in FKBP1B, PXDNL, and SCN9A Evaluated in hiPSC Cardiomyocytes. Stem Cells Int. 2020, 2020, 8842398. [CrossRef]

19. Bezzina, C.R.; Barc, J.; Mizusawa, Y.; Remme, C.A.; Gourraud, J.B.; Simonet, F.; Verkerk, A.O.; Schwartz, P.J.; Crotti, L.; Dagradi, F.; et al. Common variants at SCN5A-SCN10A and HEY2 are associated with Brugada syndrome, a rare disease with high risk of sudden cardiac death. Nat. Genet. 2013, 45, 1044-1049. [CrossRef]

20. Verkerk, A.O.; Remme, C.A.; Schumacher, C.A.; Scicluna, B.P.; Wolswinkel, R.; de Jonge, B.; Bezzina, C.R.; Veldkamp, M.W. Functional Nav1.8 channels in intracardiac neurons: The link between SCN10A and cardiac electrophysiology. Circ. Res. 2012, 111, 333-343. [CrossRef] [PubMed]

21. Peterfi, Z.; Tóth, Z.E.; Kovács, H.A.; Lázár, E.; Sum, A.; Donkó, Á.; Sirokmány, G.; Shah, A.; Geiszt, M. Peroxidasin-like protein: A novel peroxidase homologue in the human heart. Cardiovasc. Res. 2013, 101, 393-399. [CrossRef]

22. Masia, R.; Enkvetchakul, D.; Nichols, C. Differential nucleotide regulation of KATP channels by SUR1 and SUR2A. J. Mol. Cell. Cardiol. 2005, 39, 491-501. [CrossRef] [PubMed]

23. Noma, A. ATP-regulated K+ channels in cardiac muscle. Nat. Cell Biol. 1983, 305, 147-148. [CrossRef]

24. Nichols, C.G.; Ripoll, C.; Lederer, W.J. ATP-sensitive potassium channel modulation of the guinea pig ventricular action potential and contraction. Circ. Res. 1991, 68, 280-287. [CrossRef]

25. Hu, D.; Barajas-Martinez, H.; Terzic, A.; Borggrefe, M.; Veltmann, C.; Schimpf, R. Compound mutations in ABCC9 and SCN5A associated with a malignant form of overlap syndrome: Brugada, long QT and early repolarization syndromes. Heart Rhythm 2011, 8, S463.

26. Mohler, P.J.; Schott, J.-J.; Gramolini, A.O.; Dilly, K.W.; Guatimosim, S.; Dubell, W.H.; Song, L.-S.; Haurogné, K.; Kyndt, F.; Ali, M.E.; et al. Ankyrin-B mutation causes type 4 long-QT cardiac arrhythmia and sudden cardiac death. Nat. Cell Biol. 2003, 421, 634-639. [CrossRef]

27. Lowe, J.S.; Palygin, O.; Bhasin, N.; Hund, T.J.; Boyden, P.A.; Shibata, E.; Anderson, M.E.; Mohler, P.J. Voltage-gated Nav channel targeting in the heart requires an ankyrin-G-dependent cellular pathway. J. Cell Biol. 2008, 180, 173-186. [CrossRef] [PubMed] 
28. Cerrone, M.; Lin, X.; Zhang, M.; Agullo-Pascual, E.; Pfenniger, A.; Gusky, H.C.; Novelli, V.; Kim, C.; Tirasawasdichai, T.; Judge, D.; et al. Missense Mutations in Plakophilin-2 Cause Sodium Current Deficit and Associate with a Brugada Syndrome Phenotype. Circulation 2014, 129, 1092-1103. [CrossRef]

29. Hu, D.; Viskin, S.; Oliva, A.; Carrier, T.; Cordeiro, J.M.; Barajas-Martinez, H.; Wu, Y.; Burashnikov, E.; Sicouri, S.; Brugada, R.; et al. Novel mutation in the SCN5A gene associated with arrhythmic storm development during acute myocardial infarction. Heart Rhythm 2007, 4, 1072-1080. [CrossRef] [PubMed]

30. Oliva, A.; Hu, D.; Viskin, S.; Carrier, T.; Cordeiro, J.M.; Barajas-Martínez, H.; Wu, Y.; Burashnikov, E.; Brugada, R.; Rosso, R.; et al. SCN5A Mutation associated with acute myocardial infarction. Leg. Med. 2009, 11, S206-S209. [CrossRef]

31. Fatovich, D.M. Delayed lethal arrhythmia after an electrical injury. Emerg. Med. J. 2007, 24, 743. [CrossRef]

32. Cordeiro, J.M.; Nesterenko, V.V.; Sicouri, S.; Goodrow Jr, R.J.; Treat, J.A.; Desai, M.; Wu, Y.; Doss, M.X.; Antzelevitch, C.; Di Diego, J.M. Identification and characterization of a transient outward K+ current in human induced pluripotent stem cell-derived cardiomyocytes. J. Mol. Cell. Cardiol. 2013, 60, 36-46. [CrossRef]

33. Vaidyanathan, R.; Markandeya, Y.S.; Kamp, T.J.; Makielski, J.C.; January, C.T.; Eckhardt, L.L. IK1-enhanced human-induced pluripotent stem cell-derived cardiomyocytes: An improved cardiomyocyte model to investigate inherited arrhythmia syndromes. Am. J. Physiol. Circ. Physiol. 2016, 310, H1611-H1621. [CrossRef]

34. Calloe, K.; Chlus, N.; Nof, E.; Jespersen, T.; Olesen, S.-P.; Antzelevitch, C.; Cordeiro, J.M. Comparison of the Effects of the Transient Outward Potassium Channel Activator NS5806 on Canine Atrial and Ventricular Cardiomyocytes. Biophys. J. 2010, 98, 334a. [CrossRef]

35. Veerman, C.C.; Mengarelli, I.; Lodder, E.M.; Kosmidis, G.; Bellin, M.; Zhang, M.; Dittmann, S.; Guan, K.; Wilde, A.A.M.; SchulzeBahr, E.; et al. Switch From Fetal to Adult SCN5A Isoform in Human Induced Pluripotent Stem Cell-Derived Cardiomyocytes Unmasks the Cellular Phenotype of a Conduction Disease-Causing Mutation. J. Am. Heart Assoc. 2017, 6. [CrossRef] [PubMed]

36. Calloe, K.; Aistrup, G.L.; Di Diego, J.M.; Goodrow, R.J.; Treat, J.A.; Cordeiro, J.M. Interventricular differences in sodium current and its potential role in Brugada syndrome. Physiol. Rep. 2018, 6, e13787. [CrossRef] [PubMed]

37. Treat, J.A.; Goodrow, R.J.; Bot, C.T.; Haedo, R.J.; Cordeiro, J.M. Pharmacological enhancement of repolarization reserve in human induced pluripotent stem cells derived cardiomyocytes. Biochem. Pharmacol. 2019, 169, 113608. [CrossRef] [PubMed]

38. Calloe, K.; Goodrow, R.; Olesen, S.-P.; Antzelevitch, C.; Cordeiro, J.M. Tissue-specific effects of acetylcholine in the canine heart. Am. J. Physiol. Circ. Physiol. 2013, 305, H66-H75. [CrossRef] [PubMed]

39. Barajas-Martinez, H.; Goodrow, R.J.; Hu, D.; Patel, P.; Desai, M.; Panama, B.K.; Treat, J.A.; Aistrup, G.L.; Cordeiro, J.M. Biophysical and molecular comparison of sodium current in cells isolated from canine atria and pulmonary vein. Pflügers Arch. Eur. J. Physiol. 2017, 469, 703-712. [CrossRef]

40. Goodrow, R.J.; Desai, S.; Treat, J.A.; Panama, B.K.; Desai, M.; Nesterenko, V.V.; Cordeiro, J.M. Biophysical comparison of sodium currents in native cardiac myocytes and human induced pluripotent stem cell-derived cardiomyocytes. J. Pharmacol. Toxicol. Methods 2018, 90, 19-30. [CrossRef] [PubMed]

41. Cordeiro, J.M.; Bridge, J.; Spitzer, K. Early and delayed afterdepolarizations in rabbit heart Purkinje cells viewed by confocal microscopy. Cell Calcium 2001, 29, 289-297. [CrossRef] [PubMed] 